\title{
A case analysis on creative school management in Mainland China
}

\author{
Wu, Su Ching $\triangle \triangle$
}

Department of Education, National ChengChi University, Taiwan, ROC(wsj@nccu.edu.tw)

Po, Chan Yu

Graduate Institute of Chinese Studies, Chinese Culture University, Taiwan, ROC (pochanyu@ms58.hinet.net)

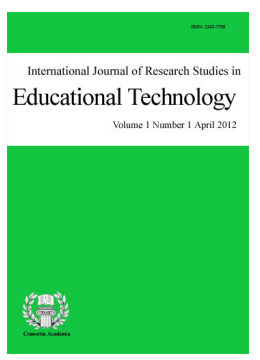

ISSN: $2243-7738$ Online ISSN: 2243-7746

OPEN ACCESS

\section{Abstract}

This paper provides an insight on the why and how schools in China go about their creative changes. A historical view is given with implications for change. Using a documentary analysis research paradigm, this paper shall open up issues and trends that can provide as a basis of comparison and exemplar for other school.

Keywords: creative management; school innovation; technological advancement; China 


\section{A case analysis on creative school management in Mainland China}

\section{Introduction}

Since the policy building of 1949, the educational development of the Mainland China receives a strong political backing. With the implementation of the policy of reform in 1979, China started to open up to the outside world. With the influence of globalization, educational developments have been focused on academic excellence. For the last ten years, China has increased its national income dramatically. Furthermore, with the 'one child policy', parents; who are economically capable, have started to demand for better education. Hence, schools have begun to innovate and embrace creative management schemes.

\section{School environments}

A child grows studying inside the school. So it's but natural that the first focus would be on the school grounds. More importantly, focus is placed on the environmental school changes, in order words the architectural design of the school (Xie, 2007). It is said that a building is not the isolated existence; it always produces a close connection with its region or environment.

Take a star primary school in Beijing as an example; the school consists of primary and kindergarten levels. Designers try to integrate the idea of a whole school. The close linkages of the two organizations (primary and kindergarten) shape the change. It is said that providing a smooth transition from the kindergarten to the primary levels would be beneficial to all the stakeholders. Not only the students but also the teachers would benefit on such innovations.

Research shows that an isolated building brings negative influence to children, on the contrary, when one incorporates the building with the environment; this will bring a more natural touch. Growing up in a place where the environment is friendly; becomes the core of educational development today. Architectural school designs emphasize the community buildings with the important background of the primary school and kindergarten at the same time. With the reduced stress have all together created a graceful integration with the environment, hence, creating interpersonal harmony. This kind of cognition contributes to helping teenager and children to respect the environment, encourage exchanges, and the cultivation of healthy psychology (Xie, 2007).

\section{Parents' participation}

Second, is to expand the participation and exchange in many ways among parents and school. In 2004, one primary school "Laoshan" in Shanghai setup a parents' committee and ask parents into campus. Parents are asked to volunteers, such as five parents from every class. This is followed with the level committees electing their representative to the school level organization. With the parents committee, core ideas on what should be the focus of the school are suggested. This means that schools are opening up to the parents' participation. Furthermore, activities are created during special occasions and holidays, to further minimized the gap among the faculty and parents. Dialogues are being done to collect feedbacks and suggestions, which in essence, improve the parents' participation and provide a sense of ownership of the school.

In addition to the previous mentioned activities, parents' committee also organizes house calls. They will visit and listen to other parents' comments and feedbacks. Many teachers usually just know to an extent the background of their students. In some ways, these committees serve as a bridge between the school and home (Pan, 2012).

An example, Shanghai Daning international primary school; this school carried out various course reforms, 
expansion of course type and offerings, in order to meet the outside demands. With an overall goal of improving the qualities of students; the school in a way is able to pay close attention to the students' holistic development $(\mathrm{Xu}, 2011)$.

In addition, the school hopes to give a certain role to the parents. In June of 2009 , the school, community and the parents have combined and established the so called "the education agenda committee" of the school; this is a merger operation through the education agenda committee. The expansion of communication between the community, family, and school; such negotiation channels shall be able to strengthen the combining effectiveness of the community, family, and the school resources.

The education agenda committee is made up of 13 people, 4 representatives of the community, 4 representatives from the parents, and 5 representatives from the school. The educational agenda committee holds the plenary session twice each term, and is mainly responsible for the understanding of the situation that the work program of the school implements. Most of their responsibilities include listening to parents' committee, putting forward the suggestion on the measure of the concrete reform of the school, feedback the suggestion and making a self-criticism to the community. It is therefore obvious that with the parents' participation and constant improvement of the school, becomes an important direction for future development (Xu, 2012).

\section{Foreign language teaching}

For time and again, many have mentioned that learning a foreign language is very important. More so, in the current time of internationalization and globalization, English language learning is a major key to school development. Within a primary school, the cultivation of the entire individual is quite important. Furthermore, the students' foreign language communication and comprehension is considered as an inseparable part. With influences is able to extend to: 1) expands cultural vision; 2) promote cognitive development; 3 ) favorable to the promotion of one's own language ability; 4) aids students in learning another language, learns other peoples' culture; 5) aids students' in reaching a higher level of foreign language ability. Meanwhile, learning foreign languages would be able to make the students developed into a better-rounded individual. In essence, learning a foreign language is the gateway to future success (Wang, 2005).

According to the language study goals, the major goal is that for primary schools (more importantly, in the coastal areas of China) to provide ample training. The basic four skills of listening, reading, writing, and speaking, should be reiterated. More so, with the current technological advancement, learning a foreign language will aid students in better expressing themselves. Students can also be able to read foreign websites and understand them more clearly. It is noted that language learning is not limited to communication, but its uses expands beyond (Wang, 2005).

In summary, several conclusions are drawn from the above discussion. Schools should strengthen the input foreign language teaching of primary school, by carrying on the investigation of the foreign language teaching of primary school organized, planned, and avoid the errors of the past. In addition, schools should pay close attention to data collection; firsthand data collection. Research should be accomplished with regards to the effectiveness on such innovative management strategies. More so with the foreign language teaching, studies should be accomplished to check the correlation of the curriculum enhancement, and pay attention on how to overcome previous disadvantages. Schools should pay attention to the analysis on attitude towards study and motive of foreign language; this is because the goal of the foreign language education of primary school is not only to trains, but to develop the language ability. More importantly one lies in passing learner's attitude to positive study of foreign language, thus the understanding of different Chinese and understanding, if the effect to the foreign language teaching of primary school, only take the way to test to carry on measurement, it is very apt to present the one-sidedness that are caused in teaching (Wang, 2005).

The demand for pupil's language ability; schools of primary school foreign language teaching, must consider the real situation. The achievement of the foreign language teaching of primary school, often come from the 
implementing of classroom instruction, to the forming of children's attitude towards study because of the classroom instruction, have the most direct function, therefore the teacher's teaching way becomes the most key factor, the teacher's language, the teacher's education theory, how classroom activity are designed, and many others. Schools have a direct impact on students' interest, motive, and cognition. Therefore, teachers are crucial. This reflects the need for better teacher training. The training of the foreign language teacher of primary school in the future, no matter before the duty or on-the-job teacher, should include the use and development of the ability, idea and skill and the skill, primary school foreign language course resource of the method, primary school foreign language teaching of primary school education of the foreign language, and the self-criticism and reform of commenting amount and relevant measures of teacher's teaching of foreign language of primary school, and many others (Wang, 2005).

In addition, the foreign language teacher of primary school must also understand child psychology, understand the characteristic and method of foreign language teaching, and use the study of foreign language to combine flexibly with other disciplines, the integration that is promoted among discipline and promotion of the study interest (Wang, 2005). Reform and innovation of the foreign language teaching of primary school, can't just put emphasis on reducing and studying the age initially, research shows, the initial age itself does not form absolute predominance in study of foreign language; Especially, the age and various kinds of other factors, influence the results of learning of foreign language together, include teacher, giving lessons in time, environment, teaching design and method, commenting amount of teaching and way, etc.; In view of the above, the research of the results of learning of should face more actively in the featuring, many kinds of age levels, is it is it suit different student of age stage teaching method to learn foreign language to appear to develop, regard rigorous science designs, true data as the innovative foundation, thus enable relevant reforms to produce positive guidance and facilitation to teaching, is it about concrete practice, can participate in international low age in the interchange, children of foreign language teaching to make furthermore (Wang, 2005).

Plan and look over the questions of linking up of the primary school and middle school foreign language teaching totally, namely primary school and middle school link up, lie in to link up language not merely, lie in attitude, study way, is it require with to link up content to study even more; the department in charge of education and teaching and research department must carry on the research of the foreign language teaching of middle and primary schools voluntarily, make the concrete measure linked up early, this is because link up and go wrong, then achievement foreign language teaching make during the primary school, will definitely all that has been achieved has come to nothing (Wang, 2005).

Review the educational development of primary school in the 20th century of China's Mainland, may well be termed the hiccup several times in its course, whether scholar point out past experience to future enlightenment, mainly. First, the scientific method that must be defined with the scientists, the standard studied for education; Second, must be with the background that the children know and cognitive characteristic, as the starting point that is educated, could really lead the children to move towards practical study; Finally, the teacher's synchronous training is especially teacher's understanding real to primary school education, it will be the condition that the primary school education achieves success (Zhang \& Yu, 2003).

At present, with the further intensification of the economic globalization, the increasing day by day of international population, the economic, cultural, political connection, connection between the countries all over the world, this mean every exchange of field reach first unprecedented scope and depth. The traditional culture is slowly being replaced into a more complex pluralistic state. Education is understood as the key to internationalization (Wang, 2011). Especially, the present situation of combining international educational development of primary school is able to show that the major future trends is to pay attention to student's studying experience and practice (Kong, 2001). This means, that the primary school education combines individualization, activity, and practicality, and focus to the students' personal feeling and differential one that learn, person who merit attention all, future China's Mainland primary school is to manage it innovatively. Direction of that reform should be followed, meanwhile, it prove primary school education in still behind 
international experience, and must still proceed from the actual conditions of China's Mainland to develop even more (Kong, 2001). This means that school should also be devoted to taking a development path with distinct Chinese characteristics while accepting new forward thinking.

\section{References:}

Kong, Q. P. (2001). Background and trend of international teaching: Educational reform of primary school [In Chinese]. Shanghai Education, 2, 18-20.

Pan, C. C. (2012). Primary school of Laoshan: Participating in the election for home-campus development [In Chinese]. Shanghai Education, 1, 25.

Wang, H. Y. (2011). Simple analysis of international course and characteristics of primary school under the globalization background [In Chinese]. After School Education for Chinese, 14, 107-118.

Wang, Q. (2005). Research and enlightenment of international primary foreign language teaching [In Chinese]. Curriculum, Teaching Material, and Method, 1, 84-90.

Xie, G. J. (2007). Beijing baoxing international elementary school and kindergarten [In Chinese]. Architectural Journal, 9, 53-55.

Xu, W. (2011). Daning international primary school of Zhabei district of Shanghai: Daning international primary school [In Chinese]. Modern Teaching, Z1, 161.

Xu, X. (2012). Daning international primary school: Teach the parliament - New way the "three sides link" [In Chinese]. Shanghai Education, 1, 25.

Zhang, H. X., \& Yu, B. (2003). The past and the present of international primary science education reform: An international perspective. Comparative Education Review, 8, 55-59. 
Wu, S. J. \& Po, C. Y. 